\title{
Recognizing the Need for Change of Work and Treatment of Elderly People with Disorders in Mental Development
}

\author{
Dr. Suzana Špendal \\ Prof. DDR. Marija Ovsenik
}

Doi:10.5901/mjss.2016.v7n2s1p127

\begin{abstract}
In the article we identify how leaders in organizationally different occupational activity centres (hereinafter OAC) recognize the daily burden of elderly users of OAC services from the perspective of work and behavioural changes. Further on, we identify possible changes in work satisfaction of people, who use OAC services, which manifest in the form of lower motivation, suffering from disease and irregular presence in the OAC. We focus on the individual approach of treating individuals, which derives from the principle of individualization, and stress out the need for social and systemic changes in the treatment of this population in old age. The article verifies findings of modern researchers on the quality of life of the elderly population of people with disorders in mental development. The questions which arise are: how to reduce the intensity of the daily program and the hours of active planning and how to change the environment of the program. Questions are also directed into providing additional (without employment) day care due to retirement and into providing accommodations for these service users. The results of the existing research reveal key-factors, typical for the elderly population of users of OAC services, aged over 50, from which is reflected the need for changes of current practices and changes in the treatment of these population.
\end{abstract}

Keywords: Elderly people with disorders in mental development, quality of life, health, spare time, OAC.

\section{Theoretical Introduction}

In literature and academic discussions some countries in their policies and expert fundaments direct their views towards modern practices of everyday life and quality coexistence of elderly people with disorders in mental development as a construct of traditional perception of programs for this population of people (Špendal, 2014).

As Ovsenik $(2011,21,23)$ stats: "Only sociological describing of the state, a critical analysis of it and moralizing about how it should be is not enough. We are talking about a new type of target orientation, systemic application and team work, which brings new empowerment for a potential service."

People with disorders in the mental development want more control over manners, considering their life, as well as more meaningful life roles. They value mental stimulation, socializing, reliable support and security, since the topics they have mostly stressed out were: to be empowered, to be actively involved, to have the sense of security, to acquire meaningful skills and learning, to have friendly relationships and to be healthy and in good shape (Buys, 2008 in Vadnal 2011, 4-5).

\section{Quality Aging of People with Disorders in Mental Development}

Janicki (1999 in Špendal, 2014) explains quality aging of the population of people with disorders in mental development as maintenance of the individual's ability to function as independently as possible in his age. It is about encouraging the belief that people, who are aging with quality, can stay outside the institution, are autonomous and maintain their competence in all activities of daily living and continue to participate in productive efforts of their own choice. Železnik $(2008,6)$ emphasises that "the goal of the treatment of the elderly should not be only the prolongation of his life, but quality aging".

According to Brown and Taylor (2001), the "quality of life in the field of work with people with disorders in mental development was presented as a developmental model (Goode, 1994 and Rinwick et al., 1996), as some sort of sociological and psychological construct. At first, some apparent disagreements about the nature of the quality of life have been identified (Wolfensberger, 1994 and Taylor, 1994) and numerous questions were directed towards new researches (Hatton, 1998). In recent years there has been a greater consensus in terms of definitions and constructs, which determine it (Brown, 1997). For example, defining the term "well-being" that has been well received in various fields. 
Felce and Perry (1997) state five fields of well-being, namely physical, material well-being, social welfare, emotional and productive well-being."

\section{Health and Changes of Elderly People with Disorders in Mental Development}

Health issues are common in old age of people with disorders in mental development. Common health issues in this population include incontinence, reduced mobility, loss of hearing, arthritis and cerebrovascular disease (Cooper, 1998). Durvasule and others (2002) find that this population faces more fatalities than the general population. The main causes of death are respiratory diseases; mostly occurring among individuals with severe disabilities.

The studies of Lifshitz (2004) find that lots of people with disorders in mental development from the sample have health issues, which started over the age of 40 . Common diseases were diabetes and weight related problems, arising from their lifestyle, eating habits and diet in the institutions. Other health issues in this population were problems with teeth, vision and hearing loss.

Pajk $(2013,3-4)$ states that the issues of this people manifest as disturbance of attention, thinking and expression, orientation, recognition of individual objects and performance of different moves. Often, these deviations manifest in emotional responses like suspiciousness, confusion, and insomnia. They may also experience problems with movement, feeding and discharging, vision and hearing.

Smolej $(1999,102)$ explains that "specifics of individuals are such that they are almost impossible to be combined into groups. But for transparency reasons we can identify groups like users with Down syndrome, epilepsy, motor disorders, additional visual, hearing and speech impairments. There are also large differences between individuals in the group".

Among physical changes of people with disorders in mental development, Hrastar $(2013,24-25)$ recognizes grey hair growth, dry and wrinkled skin, stooped posture and a decline in physical strength. Hormonal changes occur with the occurrence of osteoporosis, prostate issues and increased blood pressure. Changes in metabolism lead to obesity. At the same time, other health issues start to appear, like cardio-vascular diseases, cancer, diabetes, epilepsy, thyroid diseases, hearing and visual impairments. Due to these changes, these people can no longer function at the previous pace, become tired more quickly and need more rest.

Elderly people with disorders in mental development have probably a 2- to 4-times higher level of psychological problems than the general population (Tor and Chiu, 2002). The reason for this is a high level of dementia (Cooper, 1997).

"Regular aging companions of people with disorders in mental development are mental changes. These occur as personality changes, signs of psycho-organic syndrome (mental deterioration - reduction of mental capacities), dementia, depression and even psychotic disorders" (Hrastar, 2013, 24-25).

In this context it is necessary to know the factors of aging and recognize the behaviour that can lead to regression in the fields of health, capabilities of the individual and satisfaction of his needs.

The term quality of life can be truly understood only in the context of the individual's life. It considers objective circumstances, subjective assessment of the circumstances and personal evaluation (Brown, 1997).

The needs, desires and expectations of people with disorders in mental development in old age are similar to those of other aging people; however, the discrimination of these people in life is doubled: as the population of people with disorders in mental development and as a population from the view of a healthy lifestyle, unequal possibilities and access to all goods, accessible to the remaining population, and unequal treatment regarding equality in the society (Špendal, 2014).

\section{Individual Needs of Elderly People with Disorders in Mental Development and Planning of Services}

Summarized after the Australian Institute of health and welfare - AlHW (2002, 44-45), the needs of people with disorders in mental development are recognized as:

- biological (they include possible needs, like help in personal care, and deal with emotional deficiencies (e.g. reduction of visual acuity), with the reduction of physical fitness, muscle tone and strength, the reduction of mobility and the increase of the likelihood of physical disease);

- psychological, which include potential help or deal with personality issues (some people develop personal issues), motivation (due to the lack of stimulation), perceptive changes (the need to maintain an active mind) and personal control and choice (the need for a range of options);

- social (social needs include potential help with early retirement, planning, social networking and the role of 
changes - continuation with socializing) and social effects of biologic aging (need for transport and mobility).

In providing services to people with disorders in mental development it is necessary to originate from individual needs; this does not mean that their needs are totally satisfied, since these individuals would than become inactive and thus we would deny their right for respect (Bleeksma, 1999, 9).

According to Golob $(2013,11-12)$, it is very important, that a person with a disorder in mental development has access to necessary services of health care, specialist clinics, dentistry, physiotherapy, occupational therapy, speech pathology, psychology etc. Obstacles can often be money or a lack of knowledge about the needs and characteristics of people with disorders in mental development and alternative ways of communication and prejudice. Important services to ensure the physiological needs of these people are also service institutions in the field of health care, which carry out medical care, and social security services, who carry out domestic help services.

Satisfying psychological needs in people with disorders in mental development is more "comprehensive". It demands different profiles and competences of providers, which reach to very different fields of the individual's social and personal life and changes in the course of life" (Golob, 2013, 12-13).

The spare time plays an important role in the life of an adult person with disorders in mental development. Researchers state that with the inclusion of these individuals into spare time activities they can improve their prosperity (Špendal, 2014, 49).

Ashman and Suttie (1996) researched the social and cultural inclusion of 446 elderly people with disorders in mental development. All, except of those, who live with their families, have made to little use of social and recreational objects or travelling on their own. The authors suggested the need for training for greater autonomy in order to prepare them to be more active in the community.

Many of these individuals are accommodated in large institutions, mostly with poor options for their spare time. Bigby (1998) finds that a lot of the elderly, who were questioned were not satisfied with their spare time activities; the greatest obstacle for this is often a lack of trained personnel and finances. Even those individuals, who live in a community, can have issues.

The right to choose of people with disorders in mental development is directed towards originating from their true needs. It is necessary to pass from external help to self-help, develop a comprehensive partnership between the person with disorders in mental development and his peers, parents and teachers. It is important that people with disorders in mental development reach such rights in all life functions, which will satisfy their true needs, and reach true participation in the integration, not only physical integration, which will impose an unfair relation towards people with disorders in mental development (Lačen, 2001, 23-24).

In Great Britain and the US (Hogg and Moss 1993) and also in Australia started special early retirement, programs for aging people, but it was obvious that a lot of the elderly did not have a clue, what is retirement and what they can expect in this period of life. Ashman and others (1995) find that a lot of those, who visit OACs, for example have a hard time to think about retirement or decisions, which will be connected with their lives after they will stop visiting the workshops. Even in Slovenia, "we cannot formally talk about retirement of these people, like it is defined in the Act ZPIZ, but we can talk about the meaning, when they will no longer be obliged to go to work to the OACs, if any still go there. Some of the questioned users have still an unclear presentation about what retirement is and how to prepare for it, they know very little about the changes, related with it. Some are well aware that they are rewarded for their work and that this reward will decrease with their decreased capabilities to work. This causes them stress, since they do not know, what will happen, when they no longer have a job, when they retire" (Roželj and others, 2013, 17).

A lot of people with disorders in mental development stay in employment programs, when they exceed the generally acceptable retirement age of 65 years. For many among them retirement represents unknown and unwanted challenges, particularly for those, who are still employed. But it is interesting that a change in the employment status does not lead into despair or unhappiness those individuals, who have already retired (Ashman and others, 1995).

Questions about retirement and support in old age usually present concern about whether new or specialized programs need to be designed only for elderly people or for people with special needs of all ages or for elderly people in general (Bigby in Haveman, 2010).

One of the most prominent researchers of life and care for this population of people, Christine Bigby (2005), has in the research "Comparative Program Options for Aging People with Intellectual Disabilities« stressed out the importance of retirement and its suitability for people with disorders in mental development, since the majority of these individuals has attended daily activity programs the majority of their lives, due to which they have also been the object of many discussions. The author explains that the findings of this study can contribute to the ongoing discussion as well as point to needs for age-specific daily programs for elderly people with disorders in mental development in Australia and other countries. She stresses out that the daily program represents changeability of the program in terms of strategies for 
reaching key-goals. She thinks that the structural regulation and programs of models can be less important than the micro operationalization of goals. Programs should not be evaluated based on documented goals or qualitative activities. In spite of vision, individually oriented planning, which shows how important it is that each individual has an activity that matters to him, is important.

Maybe more attention should be devoted to the development and evaluation of daily programs and more focus should be given to the execution of strategies instead of thinking about new program models for elderly people. "Without a critical attitude towards past and even current theories and approaches we can hardly expect an improved approach towards changes" (Ovsenik, 2011, 24).

\section{Methodology}

In the article we research, whether there is a statistically significant difference between the leadership of organizationally different OACs regarding the recognition of needs for changes in working with an older population of service users, from three different aspects:

1. perception of changes in elderly users,

2. accepting of changes in the work with elderly users and

3. recognition of the need for individual, systematic planning of services separately for each individual.

The aims of the research were:

1. to show the needs of elderly people with disorders in mental development in Slovenian OACs;

- research the theoretical and practical aspects of principles and forms of work with the elderly with disorders in mental development;

- analyse forms of services for elderly people with disorders in mental development in the external environment;

- critically study the regulative on the integration of individuals into OACs from the perspective of work and age restrictions;

- to recognize the quantity and content of needs and possibilities for an accommodation of elderly people with disorders in mental development in old age (the question is how and in which way).

2. to show the characteristics of the organization of OACs and their leaders' inclination towards changes regarding:

- the perception of changes in elderly OAC users (health and work related, motivational, cognitive openness); own perception of changes (emotional view) in working with this population; suggestions for changes (sociosystemic, organizational, methodical); perception of the need for individual treatment of users.

These leads into the verification of the hypotheses or to the questions, whether:

- the leadership in organizationally different OACs differently perceives changes in elderly users,

- the leadership in organizationally different OACs differently perceives changes for work with the elderly population and

- organizationally different OACs perceive the need for individual, systematic planning of services separately for each individual in the same way.

\section{Sample}

The sample consists of a population of leaders of Slovenian OACs (100\%). The majority of the questioned are females $(82 \%)$, younger than 41 (41\%) or aged between 41 and 50 years (same ratio). More than a half has a college education, mostly from the field of special pedagogics and social work.

\section{Data Collection}

We collected the data with the help of an online questionnaire, which was passed to all leaders in organizationally different OACs per email at the end of 2013. The questionnaire included all the questions directed to proposals regarding changes in the organization of the life of elderly people with disorders in mental development with consideration of organizationally different OACs in Slovenia. 


\section{Results}

We processed the answers with methods of quantitative analysis with the use of the statistical software SPSS 19.0 and graphically presented them with the help of MS Excel. The data were presented in tables and graphically. The analysis was prepared in more phases. Firstly, we prepared the variables (we excluded missing answers) and checked the normal distribution of answers. We used the descriptive statistical analysis for the description of variables in the sets "Position of the users of OAC services" and "Changes of current practices" in order to obtain insight into those fields representing better and less regulated areas of the status of users and the degree of inclination to change current practices. Since individual constructs were measured with more indicators, we than performed an exploratory factor analysis in order to determine the dimensionality of individual theoretically assumed constructs and form new factors, which were later subjected to a one-way anova analysis in order to verify the differences in individual periods between different groups of respondents.

\section{1 "Position of the users of OAC services"}

"Position of the users of OAC services" refers to the general individual state of users, like the state of health and behaviour and changes, connected with their state.

We find that the lowest average value of agreement is reached with the statement "They quickly change work activities", which tends to indicate disagreement with the statement as agreement; while the highest value of agreement is reached with the statement "The feeling of security is very important for them".

The highest level of agreement exists with statements, which refer to work capabilities of individuals; the questioned therefore mostly agree that work capabilities are worsening. Further on, the middle levels of agreement exist with statements, referring to altered ways and forms of work with this population of people. The lowest level of agreement exists with the statements, referring to changes of the state of health and work activities.

The questioned mostly agree that after the termination of visitation of the OAC users are not institutionally included, but would need different work methods and a greater choice of activities, since there is a need for individual approach in providing help and for more consultations with professionals. In addition, these leaders expressed a relatively low or critical value for the statement that it is well taken care for the spare time of users.

The position of users is a three-factor construct. The first dimension of this construct refers to worsening of the state of health and physical and mental capabilities for work; we name this variable "Changes of the state of health and work capabilities". The next dimension of this construct refers to the need for an altered approach towards this population of users due to their certain characteristics; therefor the new variable is called "Need for additional motivation". The third dimension of this construct shows, that the construct "Position of users" is also defined by characteristics of users, which refer to their behaviour, the new variable is therefore called "Behavioural changes".

\section{2 "Changes of current practices"}

This set of statements refers to the systematic regulation of the position of elderly users of OAC services. We find that the variables are normally distributed, with the exception of the variable "The transition from the OAC to a more appropriate individual form for these individuals needs to be planned gradually".

The lowest average value of agreement has the statement "There is not enough personnel for work with this population in this institution" and the highest the statement "The transition from the OAC to a more appropriate individual form for these individuals needs to be planned gradually".

The highest level of agreement shows exists with statements, which refer to individual treatment of users, and the lowest with those, referring to systemic changes. The questioned expressed the lowest agreement with the statement about insufficient professionals and inadequacy of the legislation. The questioned mostly agree that services should be directed towards users, but they even more agree that it is necessary to originate from individual programs of inclusion and gradually plan the transition from OACs. Even changes in the organization of work are necessary.

"Changes of current practices" is a two-factor set. The first dimension points to systemic changes and changes in the organization, which well defines our concept, therefore we call the new factor "Changed of current practices". It turns out that this set has another dimension, which refers to the approach towards this population of users. This dimension is defined with two statements, which we can combine into one factor, which we call "Individual treatment approach". 


\subsection{1 "Perception of changes॥}

Regarding the average value of all variables measuring the perception of changes in users, we can say that changes mostly percept OACs with concession, a little less OACs as units of social welfare institutions and the least independent OACs, but the difference is not statistically significant.

Statistically significant differences manifested in the statements "Are increasingly becoming ill" and "More often need health assistance", which means that this kind of (health) changes are mostly recognized by OACs with concession than OACs as units of the social welfare institutions and in a significantly lesser extent this applies to independent OACs.

\subsection{2 »Embracing change»}

The common average value of variables of the set "Embracing changes" shows that OACs as units of the social welfare institutions are mostly prone to changes in the work with elderly users, followed by OACs with concession $(3,77)$ and finally by independent OACs, where the differences are not statistically significant.

Statistically significant differences are also seen with the statements "Often manifests a need for different methods of work with these population of people" and "They need more options regarding inclusion into everyday activities", which points to the fact that OACs as units of social welfare institutions significantly more recognize the need for changes of the methods of work with this population and that this population needs more options regarding inclusion into everyday activities than OACs with concession and even more than independent OACs.

\subsection{3 »Recognition of the need for individual, systematic planning of services separately for each individual«}

The field of recognizing the needs for individual, systematic planning of services separately for each individual was measured with two variables, but we checked, whether there are statistically significant differences in recognizing these needs among OACs concerning their organizational structure.

Concerning their organizational structure, OACs similarly recognize the needs for individual, systematic planning of services. OACs as units of social welfare institutions and OACs with concession however mostly recognize these needs, while the level of recognition among independent OACs is somewhat lower, but these differences are not statistically significant.

\section{The Interrelation of Factors from the Field of the Position of Elderly Users and Changes of Current Practises}

In checking the interrelation among factors we were mostly interested in the connection between the factors "Need for additional motivation" and "Changes of current practices", since we thought that the higher the perception of the need for additional motivation for elderly users, the greater will be the devotion to changes of current practices in working with these users and vice versa. The theoretical origins state the perception of different health indications, which in people with disorders in mental development manifest as different forms of behavioural change, which consequently demands appropriate reactions, reflected in good professional training of the personnel, methodical knowledge, appropriate communicational patterns and types of motivation for work with elderly people in the OAC. The awareness about the later directs into proper expert, personnel, legislative and systemic solutions or changes of current practices at the national level.

We find that with all interrelations of factors exists less than 1 or $5 \%$ of risk, when we claim that the factors are statistically significantly connected. The strongest connection is between the factors "Changes of current practices" and "Behavioural changes" and the factors "Changes of current practices" and "The need for additional motivation", where we evaluate the connections as very strong or strong. The connections mean that the more behavioural changes are perceived by users, the greater is the need for changes of current practices and that the greater the need for additional motivation in work with this population of users, the greater the need for changes of current practices. A medium strong connection is between the factors "The need for additional motivation" and "Behavioural changes". The factor "Changes of the state of health and capabilities" has also a medium strong connection with the remaining factors: "The need for additional motivation", "Behavioural changes" and "Changes of current practices". The factor "Orientation on individual needs" is less connected with other factors, but his connection is still high concerning the connection with the factor "Behavioural changes" and also with the factors "Changes of current practices" and "The need for additional motivation". Slightly weaker connection is detected between the pair of factors "Changes of the state of health and capabilities" and "Orientation on individual needs", where the risk for disconnectedness is also greater. 
All connections are thus statistically significant at the level $p<0.01$, with exception of the connection of the pair of factors "Changes of the state of health and capabilities" and "Orientation on individual needs", where the connection is statistically significant at the level $p<0.05$.

All connections are also positive, meaning that if we increase the value of one, the value of the other variable in the pair will also increase.

Since we particularly focused (in checking the impacts) on the connection of factors of identification "The need for additional motivation" and "Embracing changes of current practices", let us summarize that the mentioned connection is a strong positive one, which confirms the hypothesis that elderly people with disorders in mental development need changes of current practices, which can be achieved with different types of work in OACs and thus impact greater motivation in everyday activities.

\section{Conclusion}

Based on existing theories and findings of researchers, who study the quality of life of elderly people with disorders in mental development, like Bigby (2010), Brown (2001) and others, we identify important parallels, which explain and confirm the importance of independent and autonomous life of this population of people in the environment and the social network, which is friendly, well known to them and enriched in a way that enables their full participation in society.

The results of the research show that OAC leaders perceive the position of people with disorders in mental development in following ways:

- $\quad$ work capabilities of this group of users are worsening;

- $\quad$ visible are needs for altered ways and forms of work with this population of people;

- leaders least agree with statements concerning changes of the state of health and work activities of this group of users;

- $\quad$ they agree that after the termination of visitation of OACs users are not institutionally included, but that they would need other work methods and a greater selection of activities, since there is the need for an individual approach in providing help and for more consultations with professionals;

- they expressed a relatively low or critical value of agreement with the statement that it is well taken care of the spare time of users.

Changes in users are mostly perceived by OACs with concession, followed by OACs as units of social welfare institutions and the least by independent OACs, but the difference is not statistically significant.

Further, the results of the research show that leaders mostly agree with statements referring to individual treatment of users, and less agree with those, referring to systemic changes. They agree at least with the statement about insufficient number of personnel and about inadequate legislation. They agree that services should be directed more towards users and even more agree that we need to originate from individual programs of inclusion and gradually plan the transition from the OAC. They state that changes in the organization of work are also needed.

The most prone to embrace changes in the work with elderly users are OACs as units of social welfare institutions, a little led OACs with concession and at least independent OACs, whereas the differences are not statistically important.

Concerning their organizational structure, OACs similarly recognize the needs for individual, systemic planning of services. The differences are not statistically significant. We find that the strongest connection among factors from the field of the position of elderly users and change of current practices is between the factors "Changes of current practices" and "Behavioural changes" and between the factors "Changes of current practices" and "Need for additional motivations", where we evaluate the connections as very strong or strong.

We find there truly are differences between organizationally different OACs concerning their recognition of needs for changes for work with the elderly population of service users, but that they are not statistically significant. Changes are mostly perceived by OACs with concession and OACs as units of social welfare institutions, but at least by independent OACs. Statistically significant differences manifest in variables concerning changes in the state of health of users, which are mostly perceived by OACs with concession and at least by independent OACs, and also in variables concerning the perception of needs for change in the treatment of these users, which is the most significant for OACs as units of social welfare institutions and at least for independent OACs.

The findings of the conducted research in this article direct towards questions about employee motivation in such institutions as the main criterion of possible aspects of changes of current practices in this field of work and on the other side towards questions about the awareness of the needs for altered behaviour and heath indication in this population of people, which necessarily leads to a change of current practices. This is a paradoxical finding, which necessarily demands changes at the systemic level. 


\section{References}

Australian Institute of Health and Welfare. 2002. Unmet demand for disability services. Disability Data Briefing 22. Canberra: Australian Institute of Health and Welfare.

Ashman, Adrian F., Suttie, Janene and Bramley, Janny. 1995. Employment, retirement and elderly persons with developmental disabilities. Journal of Intellectual Disability Research 39 (2): 107-115.

Ashman, Adrian F. and Suttie, Janene N. 1996. Social and community involvement of older Australians with intellectual disabilities. Journal of Intellectual Disability Research 40 (2): 120-129.

Bigby, Christine. 1998. Parental Substitutes? The Roleof Siblings in the Lives of Older People with Intellectual Disability. Yournal of Gerontological Social Work 29 (1): 3-21.

--- 2005. Comparative Program Options for Aging People with Intellectual Disabilities. Journal of Policy and Practise in Intellectual Disabilities 2 (2): 75-85.

Bigby, Christine and Haveman, Milles. 2010. Aging ... A Continuing Challenge. Journal of Policy and Practice in Intellectual Disabilities 7 (1): 1-2.

Bleeksma, Marjan. 1999. Aging with a disorder in mental development. Ljubljana: Sožitje - The association of Slovenian societies to assist mentally disabled people.

Brown, Roy I. 1997. Quality of Life for People with Disabilities: Models, Research and Practice. Cheltenham: Stanley Thornes.

Brown Roy, Taylor, Janet and Matthews, Brian. 2001. Quality of life - Ageing and Down syndrome. Down Syndrome Research and Practice, 6 (3); 111-116.

Buys, Laurie. 2008. Issues of active ageing: Perceptions of older people with lifelong intellectual disability. Australian Journal of Ageing 27 (2): 67-71.

Cooper, Margaret 1998. Sharpening the focus on ageing and long term physical disability. Australian Yournal of Primary Health Care Interchange 4: 87-92.

Cooper, Sally Ann. 1997. Deficient health and social services for elderly people with learning disabilities. Journal of Intellectual Disability Research 41 (4): 331-338.

Durvasule, Seeta, Beange, Helen and Baker, Wesley. 2002. Mortality of people with intellectual disability in northern Sydney. Yournal of intellectual and Developmental Disability 27: 255-264.

Felce, David and Perry, Jonathan. 1997. Quality of life: the scope of the term and its breadth of measurement. v Quality of Life for People with Disabilities: Models, Research and Practice, ed. Roy I. Brown, 56-71. Cheltenham: Stanley Thornes.

Golob, Alenka. 2013. Recognizing the needs for servicing in aging people with a disorder in mental development. Naš zbornik 46 (4): 9 14.

Goode, D. A. (ed.). (1994). Quality of Life for Persons with Disabilities: International Perspectives and Issues. Cambridge, MA: Brookline.

Hatton, Chris. 1998. Whose quality of life is it anyway?: Some problems with the emerging quality of life consensus. Mental Retardation, 36, 104-115.

Hogg, James and Moss, Steve. 1993. Characteristics of older people with intellectual disabilities in England. International Review of Research in Mental Retardation 19: 71-96.

Hrastar, Franci. 2013. Aging of people with special needs. Naš zbornik 46 (4): 24-25.

Janicki, Matthew. 1999. Public policy and service design. V Aging rights, and quality of life, ed. Stanley Herr in Germain Weber, 289. Baltimore: Brookes Publishing Co.

Lačen, Marijan. 2001a. Adulthood of a person with a disorder in mental development. Ljubljana: The association of Slovenian societies to assist mentally disabled people.

Lifshitz, Hefziba. 2004. Ageing among persons with intellectual disability in Israel in relation to type of residence, age, and etiology. Research in Developmental Disabilities 25: 193-205.

Ovsenik, Marija. 2011. Social gero(?)ntology: the response time changes. In The collection of the I. scientific symposium of Slovenian physiotherapists, ed. Friderika Kresal, 19-33. Ljubljana: The Slovenian Association of Physiotherapists.

Pajk, Darja. 2013. Problems sneak in slowly and seamlessly. Naš zbornik 46 (4): 3-8.

Renwick, Rebecca, Brown, I. and Nagler, M. (1996). Quality of Life in Health Promotion and Rehabilitation: Conceptual Approaches, Issues and Applications. Thousand Oaks, CA: Sage.

Rožej, Simona, Plesec, Ivan and Fužir, Saša. 2013. Retirement of people with disorders in mental development. Naš zbornik 46 (4): 16 19.

Smolej, Pavle. 1999. Disabled people and aging. In The collection of lectures Aging of people with disorders in mental and physical development, ed. Cveto Uršič and Anton Zupan, 101-105. Ljubljana: The Institute of RS for rehabilitation and The Association of disabled workers of Slovenia.

Špendal, Suzana. 2014. Factors, which impact changes and the formation of a model for working with elderly people with special needs in Occupational activity centres (doctoral dissertation). Maribor: Alma Mater Europaea, European centre Maribor.

Wolfensberger, Wolf. 1994. Let's hang up 'Quality of Life' as a hopeless term. In D. Goode (ed.). Quality of Life for Persons with Disabilities: International Perspectives and Issues. Cambridge, MA: Brookline.

Taylor, S. J. 1994. In support of research on quality of life, but against QOL. In D. Goode (Ed.) Quality of Life for Persons with Disabilities: International Perspectives and Issues. Cambridge, MA: Brookline.

Tor, Janny and Chiu, Edmont. 2002. The elderly with intellectual disability and mental disorder: A challenge for old age psychiatry. 
Current Opinion in Psychiatry 15 (4): 383-386.

Vadnal, Katja. 2011. Slovenia without obstacles. Accessible at: http://www.cmepius.sil files/cmepius/userfiles/dogodki/2011/Com\&Gru\% 20kontaktni\%20seminar/Vadnal_CMEPIUS\%20izvlecek.pdf (December 20 2012).

Act Concerning Social Care of Mentally and Physically Handicapped Persons. Ur. I. RS 41/83 (January 7, 1984). 